\title{
Revisiting The Relationship Between Financial And Environmental Performance: Does Granger Causality Matter?
}

\author{
Kyungho Kim, Ajou University, South Korea
}

\begin{abstract}
This study rigorously investigates two ongoing issues about the relationship between environmental performance and financial performance: its sign (negative or positive) and direction of causation. The results from the longitudinal sample of US heavy-polluting industries between 1991 and 2005 support the positive relationship between EP and FP. We also test the Granger causal relationship by applying Arellano-Bond estimator. The results present that the causal direction is contingent on the selection of financial performance measures and on the characteristics of sub-groups classified by environmental performance. Namely, we find that the causality is valid only in high pollution-intensive industry group in terms of the one-year lagged accounting-based FP. A weak reverse direction was found only in the pollution-intensive industry group with Tobin's $q$. The findings clearly suggest that it is necessary to use a consistent estimator when examining causality with longitudinal data in a dynamic setting.
\end{abstract}

Keywords: Environmental Performance; Financial Performance; Granger Causality; Heterogeneity

\section{INTRODUCTION}

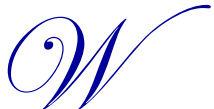

ith the increasing number of policies on environmental protection in recent years, environmental performance (EP) has become one of the main issues a firm considers when setting its scope and strategy. Reporting EP has become a widespread practice (Khanna et al., 1998). However, the question of whether EP enhances profits or merely adds to costs still remains, given that a firm must invest in better EP while complying with related rules and regulations. The relationship between EP and financial performance (FP) has been much studied since the late 1990s (Ambec and Lanoie, 2008; Griffin and Mahon, 1997; Hart and Ahuja, 1996; King and Lenox, 2002; Konar and Cohen, 2001; Nakao et al., 2007; Nehrt, 1998; Russo and Fouts, 1997; Sharma, 2002; Walley and Whitehead, 1994). Most of these studies focus on two issues regarding the relationship: the sign of the relationship (i.e., positive vis-à-vis negative relationship) and the direction of causation (i.e., which causes the other).

Some theoretical and empirical studies contend that investment in EP is positively associated with FP (Buysse and Verbeke, 2003; Hart and Ahuja, 1996; Judge and Douglas, 1998; Margolis et al., 2007; Orlitzky et al., 2003). Other studies argue that EP correlates negatively with FP because the costs associated with reducing environmental impact exceed the benefits (Freedman and Jaggi, 1994; Friedman, 1970; Greer and Bruno, 1996; Lothe et al., 1999; Walley and Whitehead, 1994). These inconsistent findings may mislead practitioners and academic researchers, calling for definite evidence on the sight of the relationship. The issue of direction of causation has been another ongoing issue in the relationship between EP and FP ( Margolis et al., 2007; Shropshire and Hillman, 2007; Waddock and Graves, 1997). It is still unclear whether FP precedes EP or vice versa.

The mixed results are caused by a lack of consensus regarding the sign and direction of the relationship and, thus, robustness checks on these empirical works are still necessary. In other words, existing studies have not yet resolved some fundamental issues, the resolution of which would clarify the sign and direction of causality of the relationship between EP and FP. These issues are the dominant dependence on either qualitative or subjective 
measures of EP; the limited access to longitudinal data; and the non-consideration of the endogenous relationship in a dynamic setting. To overcome these issues, the present study uses longitudinal data including for the objective measures of both EP and FP of US manufacturing firms. It applies a random effect model to examine the sign of the relationship in the current term by controlling for the endogeneity issue in a dynamic setting. In clarifying the direction of the causality, we use the Arellano-Bond estimator and then check the Granger causality.

In the following sections we review literature about the relationship, introduce research questions, explain methods and sample, report the results, discuss their practical and theoretical implications. Finally, the last section discusses concluding remarks and a future direction.

\section{LITERATURE REVIEW}

\section{Environmental and Financial Performance}

As noted earlier, proponents argue that investing in improved EP leads to better FP through increased efficiency, resource productivity, or innovative processes, (Hart, 1995; Pogutz and Russo, 2009; Shrivastava, 1995). Even minimal environmental investments may lead to less pollution and waste in the manufacturing process (Starik and Marcus, 2000). Such environmentally focused investments give the firm a positive reputation and contribute to long-term, cooperative relationships between the firms and many external stakeholders (Aragon-Correa and Sharma, 2003; Bansal and Roth, 2000; Buysse and Verbeke, 2003; Hart, 1995). The proponents' primary reasoning is that improvement in a process or product resulting from investments in better EP leads to better long- and short-term FP. In their longitudinal case study of Greek firms, Papagiannakis and Voudouris (2009) suggest that corporate investments in environmental improvements are closely related to long-term firm-specific capabilities such as process innovation, enhanced reputation, and unique product differentiation. Nakao et al. (2007) find from the analysis of a sample of 121 Japanese firms that EP is positively related to short-term accounting FP (i.e., ROA).

Meanwhile, the opponents contend that EP is either negatively or not significantly related to FP (Fogler and Nutt, 1975; Freedman and Jaggi, 1994; Galbreath, 2006). The costs incurred to improve compliance and reduce a firm's environmental impact exceed potential financial benefits (Friedman, 1970; Greer and Bruno, 1996; Walley and Whitehead, 1994). Production resources allocated to improve the environment could otherwise be used efficiently to increase financial benefits (Lothe et al., 1999; Palmer et al., 1995). Firms may be burdened with tremendous hidden costs merely by complying with environmental regulations (Ditz et al., 1995) or voluntarily reducing toxic emissions beyond the legal limit of environmental regulation (Arora and Cason, 1995). Birch and Moon (2004) suggest that spending profit on socially responsible activities, whether through voluntary efforts or by complying with the law, leads to negative economic returns. Galbreath (2006) finds that EP has a negative relationship with corporate FP. Therefore, one of the hypothetical questions in this study is as follows

Hypothesis 1: Is EP positively or negatively related to FP?

Recent studies have shown that there is mutual causation between EP and FP (Margolis et al., 2007; Nakao et al., 2007; Orlitzky, 2001; Waddock and Graves, 1997). Although Margolis et al. (2007) emphasize that scholars need to carefully examine the bidirectional causation, the literature has not provided sufficient statistical evidence for the causal relationship, that is, whether FP temporarily precedes EP or vice versa. This is partly because, at least until recently, researchers did not use a longitudinal dataset to unambiguously explore the direction of causality of the relationship (Strike et al., 2006). Although some event studies find that negative environmental events instantly lead to negative stock prices, such studies did not only explore long-run trends (Griffin and Mahon, 1997; Konar and Cohen, 2001) but also did not control for the endogeneity problem. In this study, we explore the dual causal relationship by employing an 18-year objective and longitudinal data from 1991 to 2008 and applying the Granger causality test (Granger, 1969; King and Lenox, 2002) to the data. In our empirical analysis, therefore, we also ask the following hypothetical question:

Hypothesis 2: Is the causal relationship between EP and FP bidirectional or unidirectional? 
An additional contribution of this study is it aims to carefully explore the two fundamental issues by controlling for the different characteristics of sub-groups, given that our sample consists of diverse industries. Different views of the EP-FP relationship emerge when differences among intra-sample sub-groups with distinct characteristics are considered (Derwall et al., 2005; Hart and Ahuja, 1996; Galbreath, 2006). Accordingly, statistical results are likely to be affected by the way the sample is constructed and narrowed. Scholars often fail to take into account different characteristics of sub-groups, and thus, miss important dimensions of the EP-FP relationship (Galbreath, 2006). This study accounts for the variation among sub-groups because analyzing the EP-FP relationship at the aggregate level may mask the true meaning of distinct sub-groups with heterogeneous firm attributes.

\section{METHODS AND SAMPLE}

First, the disagreement about the sign of the relationship can be explained by the lack of consistency in the EP and FP measures used (Griffin and Mahon, 1997; Orlitzky et al., 2003; Russo and Fout, 1997) and the use of subjective measures (Margolis et al., 2007). Konar and Cohen (2001) warn that subjective EP measures, whether direct or indirect, may cause conflicting results. Margolis et al. (2007) also find that the majority of studies employed subjective EP measures. However, EP can be measured by objective proxies (Chatterji et al., 2009). The US Environmental Protection Agency (EPA) Toxics Release Inventory (TRI) is an output-based, direct, and objective proxy for EP (Chatterji et al., 2009). Khanna et al. (1998) argue that TRI data can be used to monitor EP management because it provides investors with information on a firm's historical EP.

Alternatively, FP has been calculated using short-term accounting and long-term market value measures. In addition, existing empirical studies have selectively used either accounting- or market-based FP measures according to the availability of data or their own research purpose, resulting in mixed findings rather than reducing ambiguity. Thus, some recent empirical studies have often conflated as a methodological solution these alternative FP measures in the same model (King and Lenox, 2002; Nakao et al., 2007). This study heeds the advice of these studies and explores specifically how EP is differently related to the two alternative measures of FP.

Second, at least until recently, researchers did not use a longitudinal dataset from which to draw and fully disambiguate the direction of causation of the relationship between EP and FP (Strike et al., 2006). Mahapatra (1984) finds that a longer time period and a larger sample produce different results. Konar and Cohen (2001) argue that the ambivalent and varying relationship between EP and FP may be caused by small samples. Therefore, the present study attempts to correct these problems by employing longitudinal dynamic time-series panel data and applying a random effect model. This study uses the Arellano-Bond estimator to examine Granger causality.

\section{Sample and Data Sources}

The sample encompasses a wide range of publicly traded US firms in pollution-generating industries identified by their North American Industry Classification System (NAICS) two-digit codes (i.e., from NAICS 21 Coal Mining and Metal Mining, to NAICS 42 Chemical Wholesalers). This study uses three longitudinal databases: the EPA TRI for EP, Compustat North America (CNA) data for FP, and the Kinder, Lydenberg, and Domini index (KLD) for environmental practices. First, since 1988, EPA has compiled and published annually data on toxic chemical releases and waste management activities of industrial facilities in US territories. Second, CNA provides "information on more than 300 annual and 100 quarterly financial reports for more than 24,000 U.S. and Canadian publicly held companies." Last, since 1991, KLD has provided 80 "concern" and "strength" ratings for companies. The number of companies the KLD covers increased from 650 to around 3,000, circa 2008. Each rating indicates the presence or absence of a firm's positive or negative impacts on stakeholders including the environment. This study uses only environmental strength and concern factors. The KLD database has been widely used to measure corporate social responsibility and environmental management (Chatterji et al., 2009; Hillman and Keim, 2001; Mattingly and Berman, 2006; Rehbein et al., 2004).

The observation period was left-censored (Allison, 1984) in 1991 because the KLD data have been available only from then. We set the year 2008 as the end of the observations (so-called right-censoring) because when we started our research in early 2013, we could only complete the TRI data set until 2008. Unfortunately, a considerable number of firms were dropped from the dataset because of either missing or incomplete information. The final dataset consists of 383 firms (i.e., 1,854 firm-year observations). 


\section{Measures}

\section{Dependent and Independent Variables}

This study uses two dependent and independent variables. EP is used as the dependent variable in the EP model (i.e., FP $\rightarrow$ EP) and as the independent variable in the FP model (i.e., EP $\rightarrow$ FP). Likewise, FP is used as the dependent variable in the FP model and as the independent variable in the EP model. The International Standards Organization (ISO) defines EP as "results of an organization's management of its environmental impacts" (ISO 14031: 1999 definition 3.7). Because EPA toxic releases are used to measure EP, better EP refers to a reduction in a firm's toxic releases into the natural environment. EPA toxic releases are characterized by "relevance," "accuracy," "comparability," "availability," and "measurability" (Pogutz and Russo, 2009), representing objective output-based measures for EP. Specifically, this study uses Ln-transformed total toxic releases of a firm at a given year to control for outliers.

The accounting-based profitability measures capture the past performance of the firm and represent a projection of managerial choices ( McGuire et al., 1988; Orlitzky et al., 2003). This study uses earnings before interest and taxes (EBIT)/Sales as a short-term accounting measure for FP because it is an operating performance measure and largely unaffected by a firm's capital structure. For a specific example, the preliminary test shows that the correlation between return on sales (ROS) and EBIT/Sales was 0.8934 , and 0.6356 between return on assets (ROA) and EBIT/Sales, suggesting that EBIT/Sales can be a good proxy for other accounting measures. Alternatively, we also employed other accounting measures for robustness checks. This study measures a marketbased value by Tobin's q, which is sensitive to the capital market measure of firm rents.

\section{Subgroups with Different EP}

The relationship between EP and FP could be confounded by consolidating and then analyzing sub-groups with different EP. The EPA TRI data consist of industries with higher and lower toxic releases, so we can construct intra-sample sub-groups according to pollution intensity, which can be a proxy for measuring corporate EP. Lu and Huang (2008) attempt to refine the definition of pollution intensity by using the report, "Pollution Abatement Costs and Expenditures: 1999," issued by the US Census Bureau in November 2002. The report provides pollution abatement capital expenditures (PACE) and pollution abatement operating costs (PAOC). Like Tobey (1990) and Levinson (1996), $\mathrm{Lu}$ and Huang calculate the pollution intensity for the 20 three-digit NAICS manufacturing industries by dividing the summation of PACE and PAOC of a certain industry by its total value of shipments. Then, they divided the industries into high pollution-intensive (HPPI) and pollution-intensive industry (PII) groups. The HPPI group primarily includes metal manufacturing, petroleum and coal products, paper, chemical, nonmetallic mineral products, food, leather and allied products, fabricated metal products, textile, and wood products. The PII group includes plastic and rubber products; printing and related support activities; electrical equipment, appliance, and components; furniture and related products; and computer and electronic products. By directly applying these definitions, we segmented our sample into three sub-groups: HPII, PII, and "Others."

\section{Controls}

Firms tend to respond in different ways to regulatory or societal demands depending on their environmental practices (Hart, 1995; Orlitzky, 2001; Porter and van der Linde, 1996), discretionary slack (Bourgeois and Singh, 1983), firm size (Bowen, 2002; Strike et al., 2006), proportion of capital expenditures (CAPX) to growth and emissions compliance (Hart and Ahuja, 1996), and institutional and economic conditions (Dahlmann, 2009). The present study directly uses the KLD factors as a proxy for environmental practices, where KLD concern factors indicate the negative effect on the natural environment and KLD strength factors indicate the positive effect on the natural environment. Given that KLD strength and concern factors represent different constructs (Mattingly and Berman, 2006) (), we used separate total concern and strength scores (Chatterji et al., 20007). We used three slack variables, namely available (i.e., current assets/current liabilities), potential (i.e., debt/equity), and recoverable (i.e., selling, general, and administrative expenses/sales) slack because each type of slack affords managers different discretions, which are estimated to have distinct effects. We measured as the $4^{\text {th }}$ root of sales as a proxy for firm size 
to control for the heteroscedasticity problem. This factor is expected to have mixed effects on toxic releases. We also controlled for macroeconomic and governmental factors such as GDP, EPA budget discretion, and oil price.

\section{Statistical Methods}

When we investigated the relationship between EP and FP, we tried to resolve some of the endogeneity issues found in the longitudinal data. We first analyzed how the relationship changes by the cross-sectional differences within a year. Then, we examined the dynamic causal relationship. To address these two aims simultaneously, we applied a random effect model to the longitudinal data. We adopted a random effect model over a fixed effect model; the former is useful for a marginal analysis because it treats the individual effects as independent and identically distributed variables. On the other hand, a fixed effect model is a conditional analysis, which measures the individual effect of an explanatory variable on a dependent variable.

To investigate whether toxic releases are positively or negatively associated with either EBIT/Sales or Tobin's q, this study applied the following RE estimation equation (Equation 1):

$\mathrm{EP}_{t}=\mathrm{f}\left(\right.$ constant term $+\mathrm{FP}_{i, t}+$ control variables ${ }_{i, t}+$ error term $)$

(Equation 1)

Where, $\mathrm{EP}=$ Ln-transformed total toxic releases reported to the EPA in year $\mathrm{t}$

$\mathrm{FP}=\mathrm{EBIT} /$ Sales and Tobin's $\mathrm{q}$ in year $\mathrm{t}$

Next, we explored the causality between EP and FP with respect to the endogeneity issue. Statistically speaking, we used the estimator after a robust estimation on the variance-covariance matrix, and then showed the coefficient's statistical significance. Specifically, in treating autocorrelation due to the presence of a lagged dependent variable among regressors and the individual effects, characterizing the heterogeneity among the individuals, we used the Arellano-Bond estimator. Arellano and Bond developed this estimator to resolve the endogeneity issue, which arose in our study when we included a dependent variable in the right-hand side of the cross-sectional first-difference model because both dependent and independent variables were not strictly exogenous with the past and current errors. They showed that using lagged variables instead of the first-difference variables eliminates dynamic panel bias, which can result from the positive correlation between a regressor and errors. In addition, the homogeneity assumptions were imposed on the coefficients of lagged dependent variables when, in fact, the patterns of dynamics are heterogeneous across the panel, so the estimated errors are resolved by the bootstrapping iteration on the variance-covariance matrix in the random effect model. Because we controlled the fixed individual effects, we efficiently estimated the variance-covariance matrix.

According to the sign and significance of the estimators, we detected the Granger causality; we tested the hypothesis that the coefficients associated with each leading indicator are significant. We also examined the overall significance of all lagged values by the F-test. The following are regression equations for testing dual Granger causality, where $t$ denotes time and $p$ time-lagged year:

$\mathrm{EP}_{\mathrm{i}, \mathrm{t}}=($ constant term $)+\Sigma_{\mathrm{j}=\mathrm{i}, \mathrm{p}} \gamma^{(\mathrm{j})}(\mathrm{EP})_{\mathrm{i}, \mathrm{t}-\mathrm{j}}+\Sigma_{\mathrm{j}=0, \mathrm{p}} \beta_{1}{ }^{(\mathrm{j})}(\mathrm{FP})_{\mathrm{i}, \mathrm{t}-\mathrm{j}}+\left(\right.$ control variables $\left.\mathrm{i}_{\mathrm{i}, \mathrm{t}}\right)+($ error term $)$

(Equation 2)

$\mathrm{FP}_{\mathrm{i}, \mathrm{t}}=($ constant term $)+\Sigma_{\mathrm{j}=\mathrm{i}, \mathrm{p}} \gamma^{(\mathrm{j})}(\mathrm{FP})_{\mathrm{i}, \mathrm{t}-\mathrm{j}}+\Sigma_{\mathrm{j}=0, \mathrm{p}} \beta_{2}{ }^{(\mathrm{j})}(\mathrm{EP})_{\mathrm{i}, \mathrm{t}-\mathrm{j}}+\left(\right.$ control variables $\left._{\mathrm{i}, \mathrm{t}}\right)+($ error term $)$

(Equation 3)

Equations 2 and 3 include one-year and two-year time-lagged dependent and independent variables on the right-hand side to apply the Granger test. That is, if the estimated values of the coefficients in Equations 2 and 3, $\beta_{1}{ }^{(j)}$ and $\beta_{2}{ }^{(j)}$, do not differ significantly from zero, FP and EP are causal factors. In addition, including a time-lagged dependent variable allows researchers to control for autocorrelation (Cameron and Trivedi, 2009; Keele and Kelly, 2006). 


\section{RESULTS}

The purpose of this study was to explore the association between EP and FP, specifically the association's sign and causal direction. Table 1 summarizes the descriptive statistics including the means, standard deviations, and ranges of the variables.

Table 2 reports the correlations between the variables used in this study. Pairwise correlations that are significant at the $5 \%$ level are indicated by a star. We discuss a few noteworthy variables before we examine the sign and causality between EP and FP. First, the correlation table reports that toxic releases have different correlations to short-run accounting profitability and long-run market-based measures; the correlation is positive in the case of EBIT/Sales and negative in the case of Tobin's q. The statistical evidence shows that the relationships are significant, implying that the relationship between EP and FP can be contingent on how the FP of a firm is measured. In the following sections, we examine the relationship and check the robustness of the results with respect to this concern. Second, all KLD scores, in general, are positively related with toxic releases at the 5\% significance level. Because in general, we have seen that KLD scores follow a negative trend according to the KLD strength factors, our results in Table 2 are unexpected and the sign needs to be further examined in the following regression analysis.

Table 1. Descriptive Statistics

\begin{tabular}{llccccc}
\hline \multicolumn{1}{c}{ Category } & \multicolumn{1}{c}{ Variables } & Obs. & Mean & Std. Dev. & Min & Max \\
\hline \multirow{2}{*}{ KLD Scores } & Total Concerns & 3790 & .6712 & 1.0942 & 0 & 6 \\
& Total Strengths & 3790 & .3533 & .6698 & 0 & 4 \\
\hline EP & Ln Toxic Releases & 3790 & 11.2518 & 3.6886 & -10.1912 & 19.9317 \\
\hline \multirow{2}{*}{ Slack } & Available & 3659 & 1.8711 & .8449 & .2068 & 4.9915 \\
& Potential & 3552 & .7427 & .8460 & -4.8167 & 6.9306 \\
& Recoverable & 2072 & .2496 & .7597 & .0010 & 6.8581 \\
\hline \multirow{2}{*}{ FP } & EBIT/Sales & 3790 & .1133 & .0907 & -1.5961 & .5210 \\
& Tobin's q & 3776 & .7097 & .2837 & -.1373 & 2.8529 \\
\hline \multirow{2}{*}{ Firm } & Firm Size (4 $\sqrt{\text { th }}$ Sales) & 3790 & 7.7926 & 2.9152 & 2.3707 & 25.5338 \\
Attributes & CAPX/Sales & 3790 & .0643 & .0688 & 0 & 1.1347 \\
\multirow{2}{*}{ Macro } & GDP (Unit: Billion \$) & 3790 & 11333.54 & 2518.361 & 5992.1 & 14441.4 \\
& Oil Price & 3790 & 47.2153 & 26.5978 & 14.42 & 99.67 \\
& EPA Budget (Unit: Million \$) & 3790 & 7623.883 & 535.9418 & 6094.92 & 8365.42 \\
\hline
\end{tabular}

Table 2. Correlation Matrix

\begin{tabular}{|c|c|c|c|c|c|c|c|c|c|c|c|c|}
\hline & 1 & 2 & 3 & 4 & 5 & 6 & 7 & 8 & 9 & 10 & 11 & 12 \\
\hline 1 & 1 & & & & & & & & & & & \\
\hline 2 & $.0458 *$ & 1 & & & & & & & & & & \\
\hline 3 & $-.2236^{*}$ & $.1648 *$ & 1 & & & & & & & & & \\
\hline 4 & $.1853^{*}$ & $.1394 *$ & $-.1298 *$ & 1 & & & & & & & & \\
\hline 5 & $.2963 *$ & $.1137^{*}$ & $-.0847 *$ & $-.0388 *$ & 1 & & & & & & & \\
\hline 6 & $-.2878 *$ & $-.0401^{*}$ & $.1505^{*}$ & $-.1206^{*}$ & $-.4221 *$ & 1 & & & & & & \\
\hline 7 & $.1633^{*}$ & -.0238 & $.0498 *$ & $.0474 *$ & $.0930 *$ & $-.2777 *$ & 1 & & & & & \\
\hline 8 & $-.0636^{*}$ & -.0073 & $-.0710 *$ & .0203 & $-.2111 *$ & $.0841^{*}$ & $-.0531 *$ & 1 & & & & \\
\hline 9 & $.4721 *$ & $.0382 *$ & $-.2513^{*}$ & $.1471 *$ & $.5154^{*}$ & $-.3093 *$ & $.1231^{*}$ & $-.1071^{*}$ & 1 & & & \\
\hline 10 & $.1520 *$ & $.0384 *$ & $-.0683 *$ & $.0388 *$ & $.3318^{*}$ & $-.1409 *$ & -.0071 & $-.0553 *$ & $.2460 *$ & 1 & & \\
\hline 11 & $.1733^{*}$ & $-.0345^{*}$ & $.1389 *$ & -.0269 & $-.0708 *$ & $.1390^{*}$ & $.0490 *$ & $.0657^{*}$ & $.0387 *$ & $.0527 *$ & 1 & \\
\hline 12 & $.1564 *$ & -.0271 & $.1157^{*}$ & -.0196 & $-.0647 *$ & $.1362 *$ & .0170 & .0377 & $.0352 *$ & $.0772 *$ & $.8850 *$ & 1 \\
\hline 13 & $.1085^{*}$ & $-.0471 *$ & $.0874 *$ & $-.0473 *$ & $-.0546 *$ & $.0773 *$ & $.0768^{*}$ & $.0776^{*}$ & .0171 & $-.0458 *$ & $.5839 *$ & $.1966^{*}$ \\
\hline
\end{tabular}

(1) Ln Toxic Releases (Ln TR), (2) EBIT/Sales, (3) Tobin's q (TQ), (4) CAPX/Sales, (5) Firm Size, (6) Available Slack, (7) Potential Slack, (8) Recoverable Slack, (9) Total Concerns, (10) Total Strengths, (11) GDP, (12) Oil Price, (13) EPA Budget

\section{Results for the sign between EP and FP}

Table 3 presents the results estimated from the concurrent EP model (i.e., Equation 1), which sets Lntransformed toxic releases as a dependent variable. With the concurrent EP model, we estimated whether toxic 
releases are positively or negatively related to EBIT/Sales and Tobin's q (i.e., Hypothesis 1). As shown in Table 3, we regressed toxic releases on both FP measures in the pooled sample and then in three sub-groups to more carefully investigate the relationship while controlling for confounding effects in each model, where Models 1, 2, 3, and 4 indicate the pooled sample, HPII, PII, and Others group, respectively. For easy comparison, in each model, we placed the EBIT/Sales $\rightarrow E P$ and Tobin's $q \rightarrow E P$ analyses parallel to each other, where Models 1a, 2a, 3a, and 4a have EBIT/Sales as an independent variable, while Models $1 b, 2 b, 3 b$, and $4 b$ have Tobin's $q$ as an explanatory variable. Toxic releases were negatively related to EBIT/Sales and Tobin's $q$ at either $p<0.05$ or $p<0.01$ across all groups (except for the Others peer group in the case of EBIT/Sales), supporting the proponent's argument that corporate EP is positively related to FP, and that "doing good" leads to "doing better."

We found expected, unexpected, and mixed results across the models with regard to the effect of the control variables. Only available slack is significantly (and positively) related to toxic releases. This result suggests that different slack resources have distinct effects on EP (Daniel et al., 2004). Potential slack, in particular, has a significant effect on EP such that an unit increase in potential slack leads to a $20 \%$ change, on average, in the EP. With regard to the firm attributes, we found that firm size, measured by the $4^{\text {th }}$ root of assets, increases toxic releases: a unit increase in firm size increases toxic releases by $22 \sim 23 \%$ in a full sample. This result suggests that large firms are more likely to generate toxic materials, thus worsening their EP. CAPX is also positively correlated with toxic releases, an unexpected result, implying that continued corporate investment to improve the natural environment does not necessarily reduce toxic releases. We leave the possible explanations for these unexpected results in some control variables to future research. Another interesting finding is that KLD total concern and strength factors showed expected positive and negative relationships with toxic releases at significant levels, respectively. In the correlation analysis, we found that KLD strength factors have an unexpected positive relationship with EP, but when controlling for other influencing factors in the regression analysis, the statistical results show that the KLD strength factors are negatively related to toxic releases, as expected. This finding supports the argument of the natural resource-based view (NRBV) (Hart, 1995; Hart and Ahuja, 1996) that firms pursuing a proactive environmental strategy such as "Pollution Prevention" are more likely to improve EP, but firms adopting a reactive environmental strategy such as "Hazard Waste" are likely to harm he natural environment. 


\begin{tabular}{|c|c|c|c|c|c|c|c|c|c|}
\hline & & \multicolumn{2}{|c|}{ Model 1 (Full) } & \multicolumn{2}{|c|}{ Model 2 (HPII) } & \multicolumn{2}{|c|}{ Model 3 (PII) } & \multicolumn{2}{|c|}{ Model 4 (Others) } \\
\hline & & $\begin{array}{l}\text { Model 1a } \\
\text { (Ln TR) }\end{array}$ & $\begin{array}{l}\text { Model 1b } \\
\text { (Ln TR) }\end{array}$ & $\begin{array}{c}\text { Model 2a } \\
\text { (Ln TR) }\end{array}$ & $\begin{array}{c}\text { Model 2b } \\
\text { (Ln TR) }\end{array}$ & $\begin{array}{l}\text { Model 3a } \\
\text { (Ln TR) }\end{array}$ & $\begin{array}{c}\text { Model 3b } \\
\text { (Ln TR) }\end{array}$ & $\begin{array}{l}\text { Model 4a } \\
\text { (Ln TR) }\end{array}$ & $\begin{array}{c}\text { Model 4b } \\
\text { (Ln TR) }\end{array}$ \\
\hline Firm & Size & $\begin{array}{l}.223 * * * \\
(.0510)\end{array}$ & $\begin{array}{l}.233 * * * \\
(.0511)\end{array}$ & $\begin{array}{c}.184 * * \\
(.0903)\end{array}$ & $\begin{array}{l}.160 * \\
(.0857)\end{array}$ & $\begin{array}{l}.263 * * * \\
(.0873)\end{array}$ & $\begin{array}{l}.264 * * * \\
(.0904)\end{array}$ & $\begin{array}{l}.268 * * * \\
(.0798)\end{array}$ & $\begin{array}{l}.304 * * * \\
(.0810)\end{array}$ \\
\hline Attributes & CAPX/Sales & $\begin{array}{l}1.657^{*} \\
(.8710)\end{array}$ & $\begin{array}{l}1.3060 \\
(.8570)\end{array}$ & $\begin{array}{l}-2.6060 \\
(2.3360)\end{array}$ & $\begin{array}{l}-3.2610 \\
(2.3160)\end{array}$ & $\begin{array}{l}4.145^{* * * *} \\
(1.5800)\end{array}$ & $\begin{array}{l}4.468^{* * * *} \\
(1.6110)\end{array}$ & $\begin{array}{c}2.164^{*} \\
(1.1220)\end{array}$ & $\begin{array}{c}2.216^{* *} \\
(1.0820)\end{array}$ \\
\hline Slack & $\begin{array}{l}\text { Available } \\
\text { Potential } \\
\text { Recoverable }\end{array}$ & $\begin{array}{l}-.0023 \\
(.0746) \\
.201 * * * \\
(.0566) \\
.0544 \\
(.0910) \\
\end{array}$ & $\begin{array}{l}-.0047 \\
(.0747) \\
.234 * * * \\
(.0567) \\
.0501 \\
(.0910) \\
\end{array}$ & $\begin{array}{l}.1700 \\
(.1300) \\
.1760 \\
(.1130) \\
.1050 \\
(.2530) \\
\end{array}$ & $\begin{array}{c}.1620 \\
(.1310) \\
.270 * * \\
(.1140) \\
.1170 \\
(.2430) \\
\end{array}$ & $\begin{array}{l}-.1150 \\
(.1230) \\
.202 * * \\
(.0811) \\
-.0476 \\
(.1030) \\
\end{array}$ & $\begin{array}{l}-.1340 \\
(.1250) \\
.217 * * * \\
(.0829) \\
-.0100 \\
(.1050) \\
\end{array}$ & $\begin{array}{c}-.0623 \\
(.1240) \\
.189 * * \\
(.0943) \\
.1190 \\
(.1550) \\
\end{array}$ & $\begin{array}{c}-.0384 \\
(.1250) \\
.219 * * \\
(.0944) \\
.1090 \\
(.1540) \\
\end{array}$ \\
\hline KLD & $\begin{array}{l}\text { Total Concerns } \\
\text { Total Strengths }\end{array}$ & $\begin{array}{l}.249 * * * \\
(.0728) \\
-.164 * * \\
(.0813) \\
\end{array}$ & $\begin{array}{l}.232 * * * \\
(.0731) \\
-.155 * \\
(.0814) \\
\end{array}$ & $\begin{array}{l}.381 * * * \\
(.1170) \\
-.456 * * * \\
(.1250) \\
\end{array}$ & $\begin{array}{l}.409 * * * \\
(.1170) \\
-.434 * * * \\
(.1250) \\
\end{array}$ & $\begin{array}{c}.0157 \\
(.1660) \\
-.336^{* *} \\
(.1700) \\
\end{array}$ & $\begin{array}{l}-.0002 \\
(.1710) \\
-.453 * * * \\
(.1740) \\
\end{array}$ & $\begin{array}{l}.235^{* *} \\
(.1170) \\
.467 * * * \\
(.1460) \\
\end{array}$ & $\begin{array}{c}.204^{*} \\
(.1180) \\
.490^{* * *} \\
(.1450) \\
\end{array}$ \\
\hline Macro & $\begin{array}{l}\text { GDP } \\
\text { Oil Price } \\
\text { EPA Budget }\end{array}$ & $\begin{array}{c}-1.706^{* * *} \\
(.5540) \\
-.0251 \\
(.1880) \\
-1.3990 \\
(.9180)\end{array}$ & $\begin{array}{c}-1.620^{* * *} \\
(.5570) \\
-.0362 \\
(.1880) \\
-1.2750 \\
(.9200)\end{array}$ & $\begin{array}{c}.1840 \\
(.9310) \\
-.3010 \\
(.3190) \\
-3.566^{* *} \\
(1.5930)\end{array}$ & $\begin{array}{l}. .1060 \\
(.9340) \\
-.1930 \\
(.3210) \\
-2.902^{*} \\
(1.6040)\end{array}$ & $\begin{array}{c}-3.314 * * * \\
(.9700) \\
.3570 \\
(.3270) \\
-.2080 \\
(1.6220)\end{array}$ & $\begin{array}{c}-2.680^{* * *} \\
(.9940) \\
.2780 \\
(.3350) \\
-.1680 \\
(1.6570)\end{array}$ & $\begin{array}{c}-3.191 * * * \\
(.9160) \\
.1030 \\
(.3050) \\
-.5500 \\
(1.4490)\end{array}$ & $\begin{array}{c}-3.034 * * * \\
(.9170) \\
.0539 \\
(.3050) \\
-.5950 \\
(1.4450)\end{array}$ \\
\hline FP & $\begin{array}{l}\text { EBIT } \\
\text { Tobin's q (TQ) }\end{array}$ & $\begin{array}{c}-1.535^{* * *} \\
(.5330)\end{array}$ & $\begin{array}{l}-.892 * * * \\
(.2380)\end{array}$ & $\begin{array}{l}-3.823 * * \\
(1.6980)\end{array}$ & $\begin{array}{c}-1.093^{* * *} \\
(.4150)\end{array}$ & $\begin{array}{c}-3.919^{* * *} \\
(.9010)\end{array}$ & $\begin{array}{c}-1.000 * * \\
(.4130)\end{array}$ & $\begin{array}{l}-.2400 \\
(.6550)\end{array}$ & $\begin{array}{l}-.840 * * \\
(.3810) \\
\end{array}$ \\
\hline Obs. & & 1854 & 1849 & 702 & 700 & 410 & 409 & 742 & 740 \\
\hline R-square & & .2020 & .2270 & .2260 & .2660 & .1340 & .1470 & .2000 & .2160 \\
\hline F-statistics & & $153.45^{* * *}$ & $161.01^{* * *}$ & $57.27 * * *$ & $61.47 * * *$ & $95.27 * * *$ & $79.35^{* * *}$ & $90.07 * * *$ & $95.41 * * *$ \\
\hline
\end{tabular}

*** $\mathrm{p}<0.01, * * \mathrm{p}<0.05,{ }^{*} \mathrm{p}<0.1$ 


\section{Results for Granger causality between EP and FP}

Another objective of this study was to investigate the causal direction of the relationship between EP and FP (Hypothesis 2): whether FP precedes EP or vice versa. This study applied the Arellano-Bond estimator to test the Granger causality in Tables 4 and 5. Specifically, we examined whether FP precedes EP in Table 4 (Equation 2) and the reverse Granger causality in Table 5 (Equation 3).

As shown in Table 4 (i.e., FP $\rightarrow$ EP Granger causality model), we reflected the suggested statistical process (Nakao et al., 2007) on the empirical work and answered a recent theoretical question (Chatterji et al., 2009; Margolis et al., 2007; Orlitzky et al., 2003) by regressing current toxic releases on one-year and two-year lagged toxic releases, to determine whether current EP is influenced by past EP. The results show that current EP is positively related with past EP at $p<0.01$ across all models, supporting the argument that firms that have improved (harmed) the natural environment in the past are likely to do improve (harm) the natural environment in the future (Margolis et al., 2007). However, this effect holds only for EP in the previous one year. With respect to the Granger causality effect of FP on EP, the results show that one-year lagged EBIT/Sales has the expected negative effect on current toxic releases in the HPII group at a significant level and in the PII group at a marginally significant level and that the two-year lagged Tobin's q has the expected negative effect only in the HPII group at a marginally significant level, partially supporting the argument that current corporate EP is affected by past FP.

In Table 5 (i.e., EP $\rightarrow$ FP Granger causality model), we regressed current EBIT /Sales and Tobin's q on oneyear and two-year lagged toxic releases to investigate whether current corporate FP is associated with past EP. According to a recent methodological recommendation (King and Lenox, 2002; Nakao et al., 2007), we simultaneously compared the results of the accounting-based profitability measure with the market-based value measure in the same model. First, the results show that current EBIT/Sales and Tobin's q are positively influenced by the one-year lagged EBIT/Sales and Tobin's q, respectively, implying that firms with better FP in the previous year are likely to have better FP in the following year. The results also show that current EBIT/Sales is negatively related to two-year lagged EBIT/Sales. We leave the possible explanations for this unexpected result for future studies. Turning to the primary concern about the Granger causality effect of past toxic releases on current EBIT/Sales and Tobin's q, the results show that only two-year lagged toxic releases have the expected Granger causality effect on Tobin's q at a marginally significant level and only in the PII group. This finding partially (at least in the PII group) supports the argument that corporate market values take longer to affect EP. In summary, the results provide statistical evidence for the finding of a recent meta-analysis (Margolis et al., 2007) that compared the FP $\rightarrow$ EP Granger causality direction; the reverse direction was weaker. 


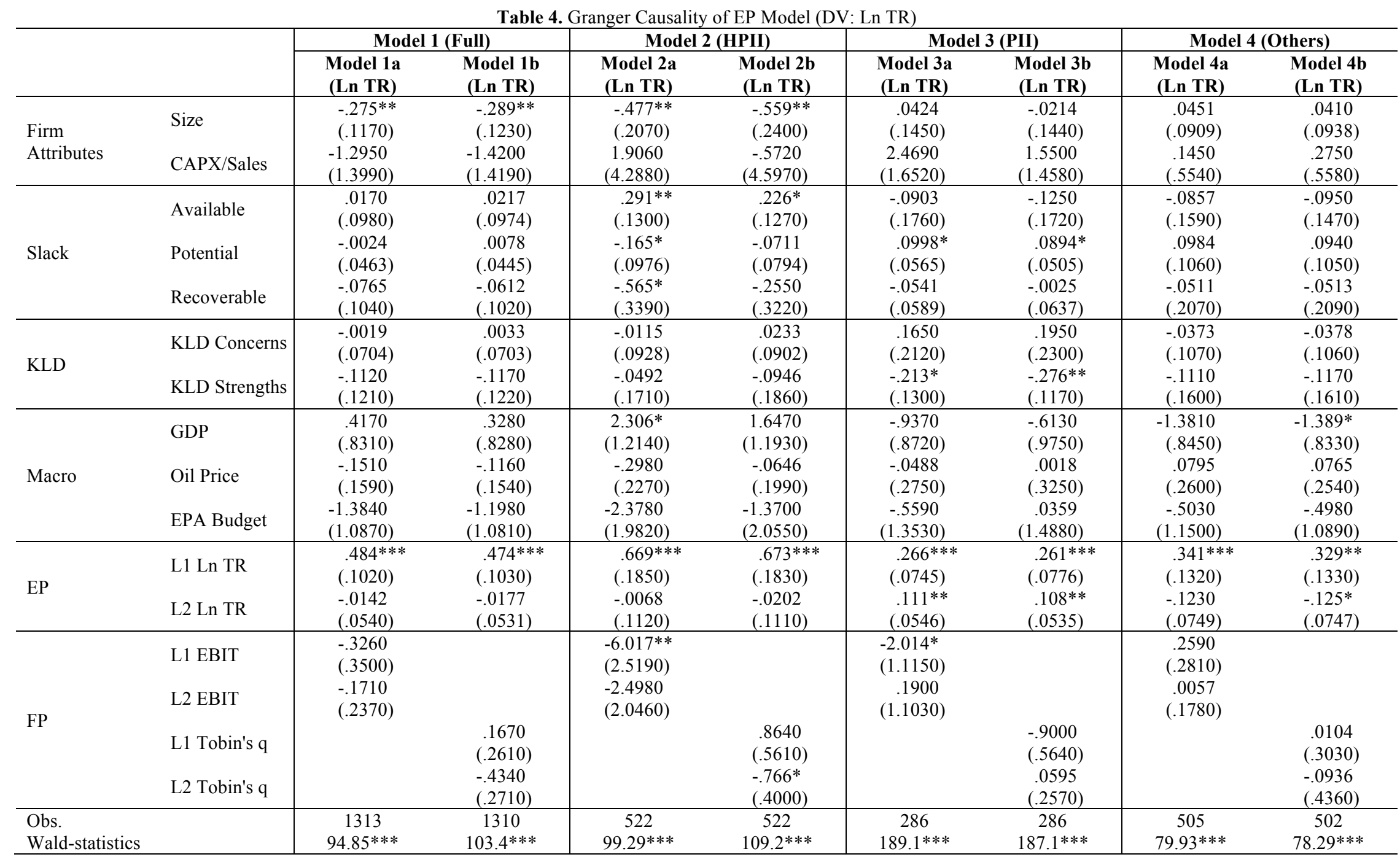

$* * * \mathrm{p}<0.01, * * \mathrm{p}<0.05, * \mathrm{p}<0.1$ 


\begin{tabular}{|c|c|c|c|c|c|c|c|c|c|}
\hline & & \multicolumn{2}{|c|}{ Model 1 (Full) } & \multicolumn{2}{|c|}{ Model 2 (HPII) } & \multicolumn{2}{|c|}{ Model 3 (PII) } & \multicolumn{2}{|c|}{ Model 4 (Others) } \\
\hline & & $\begin{array}{c}\text { Model 1a } \\
\text { (EBIT) }\end{array}$ & $\begin{array}{l}\text { Model 1b } \\
\text { (TQ) }\end{array}$ & $\begin{array}{c}\text { Model 2a } \\
\text { (EBIT) }\end{array}$ & $\begin{array}{l}\text { Model 2b } \\
\text { (TQ) }\end{array}$ & $\begin{array}{c}\text { Model 3a } \\
\text { (EBIT) }\end{array}$ & $\begin{array}{l}\text { Model 3b } \\
\text { (TQ) }\end{array}$ & $\begin{array}{c}\text { Model 4a } \\
\text { (EBIT) }\end{array}$ & $\begin{array}{l}\text { Model 4b } \\
\text { (TQ) }\end{array}$ \\
\hline \multirow{3}{*}{$\begin{array}{l}\text { Firm } \\
\text { Attributes }\end{array}$} & Size & $\begin{array}{l}.0319 * * \\
(.0133)\end{array}$ & $\begin{array}{l}.0388 * * * \\
(.0149)\end{array}$ & $\begin{array}{c}.0129 * \\
(.0075)\end{array}$ & $\begin{array}{c}.0193 \\
(.0166)\end{array}$ & $\begin{array}{c}.0437^{*} \\
(.0254)\end{array}$ & $\begin{array}{c}.0724^{*} \\
(.0415)\end{array}$ & $\begin{array}{c}.0256 \\
(.0217)\end{array}$ & $\begin{array}{l}.0495 * * \\
(.0209)\end{array}$ \\
\hline & \multirow{2}{*}{ CAPX/Sales } & .2960 & $.146^{*}$ & .0745 & .0836 & -.1750 & .2210 & $.585 * * *$ & .2300 \\
\hline & & $(.2140)$ & $(.0812)$ & $(.0536)$ & $(.1260)$ & $(.1090)$ & $(.2270)$ & $(.2230)$ & $(.1460)$ \\
\hline \multirow{6}{*}{ Slack } & \multirow{2}{*}{ Available } & $.0097 * *$ & .0076 & -.0011 & .0057 & -.0024 & -.0152 & .0059 & .0144 \\
\hline & & $(.0047)$ & $(.0087)$ & $(.0037)$ & $(.0105)$ & $(.0063)$ & $(.0205)$ & $(.0068)$ & $(.0137)$ \\
\hline & \multirow{2}{*}{ Potential } & $-.0123 * *$ & .0205 & -.0046 & .0157 & -.0015 & -.0018 & $-.0259 * *$ & .0261 \\
\hline & & $(.0059)$ & $(.0130)$ & $(.0060)$ & $(.0161)$ & $(.0034)$ & $(.0226)$ & $(.0106)$ & $(.0236)$ \\
\hline & \multirow{2}{*}{ Recoverable } & $-.0106 *$ & -.0094 & .0046 & $-.0542 * *$ & $-.0205^{* *}$ & .0064 & .0005 & -.0221 \\
\hline & & $(.0055)$ & $(.0061)$ & $(.0139)$ & $(.0211)$ & $(.0103)$ & $(.0126)$ & $(.0049)$ & $(.0165)$ \\
\hline \multirow{4}{*}{ KLD } & \multirow{4}{*}{$\begin{array}{l}\text { KLD } \\
\text { Concerns } \\
\text { KLD } \\
\text { Strengths }\end{array}$} & .0063 & -.0087 & -.0009 & .0041 & -.0119 & $-.0585 * * *$ & $.0163^{*}$ & -.0004 \\
\hline & & $(.0045)$ & $(.0075)$ & $(.0024)$ & $(.0070)$ & $(.0105)$ & $(.0204)$ & $(.0089)$ & $(.0119)$ \\
\hline & & -.0141 & -.0041 & -.0041 & -.0089 & .0019 & -.0334 & -.0480 & .0077 \\
\hline & & $(.0110)$ & $(.0075)$ & $(.0033)$ & $(.0079)$ & $(.0080)$ & $(.0257)$ & $(.0311)$ & $(.0134)$ \\
\hline \multirow{6}{*}{$\begin{array}{l}\text { Macro } \\
\text { Environment }\end{array}$} & \multirow{2}{*}{ GDP } & -.0269 & .0299 & -.0107 & .0310 & $-.116^{*}$ & .0493 & .0344 & -.0025 \\
\hline & & $(.0397)$ & $(.0572)$ & $(.0246)$ & $(.0683)$ & $(.0593)$ & $(.1670)$ & $(.0708)$ & $(.0991)$ \\
\hline & \multirow{2}{*}{ Oil Price } & -.0103 & -.0210 & -.0025 & -.0056 & -.0273 & -.0394 & -.0269 & $-.0532 *$ \\
\hline & & $(.0078)$ & $(.0160)$ & $(.0063)$ & $(.0241)$ & $(.0179)$ & $(.0478)$ & $(.0182)$ & $(.0273)$ \\
\hline & \multirow[b]{2}{*}{ EPA Budget } & -.0511 & -.0550 & -.0256 & -.0222 & -.1210 & -.0065 & -.0915 & -.0784 \\
\hline & & $(.0349)$ & $(.0746)$ & $(.0235)$ & $(.0876)$ & $(.1020)$ & $(.1800)$ & $(.0662)$ & $(.1230)$ \\
\hline \multirow{3}{*}{ EP } & L1 Ln TR & $\begin{array}{c}.0003 \\
(.0012)\end{array}$ & $\begin{array}{c}.0055^{*} \\
(.0031)\end{array}$ & $\begin{array}{l}-.0003 \\
(.0014)\end{array}$ & $\begin{array}{c}.0040 \\
(.0038)\end{array}$ & $\begin{array}{l}-.0017 \\
(.0019)\end{array}$ & $\begin{array}{c}.0092 \\
(.0095)\end{array}$ & $\begin{array}{l}-.0041 \\
(.0025)\end{array}$ & $\begin{array}{l}-.0022 \\
(.0042)\end{array}$ \\
\hline & \multirow{2}{*}{ L2 Ln TR } & -.0014 & .0035 & -.0014 & -.0048 & $-.00508 *$ & .0074 & -.0012 & .0041 \\
\hline & & $(.0015)$ & $(.0057)$ & $(.0013)$ & $(.0065)$ & $(.0029)$ & $(.0170)$ & $(.0016)$ & $(.0039)$ \\
\hline \multirow{6}{*}{ FP } & \multirow[t]{2}{*}{ L1 EBIT } & -.0293 & & $.337 * * *$ & & $.480 * * *$ & & $-.133 * * *$ & \\
\hline & & $\begin{array}{l}(.0911) \\
148 * * *\end{array}$ & & (.1140) & & $(.0571)$ & & $(.0489)$ & \\
\hline & L2 EBIT & $-.148 * * *$ & & -.0867 & & $-.502 * * *$ & & $-.111 * * *$ & \\
\hline & \multirow{2}{*}{ L1 Tobin's q } & & $.335^{* * *}$ & & $.385^{* * *}$ & & $.269 * * *$ & & $.241 * *$ \\
\hline & & & $(.0843)$ & & $(.0932)$ & & $(.0825)$ & & $(.1080)$ \\
\hline & L2 Tobin's q & & $\begin{array}{c}.0132 \\
(.0510)\end{array}$ & & $\begin{array}{l}-.0757 \\
(.0546)\end{array}$ & & $\begin{array}{l}.0478 \\
(.0824)\end{array}$ & & $\begin{array}{c}.0061 \\
(.0483)\end{array}$ \\
\hline \multirow{2}{*}{\multicolumn{2}{|c|}{$\begin{array}{l}\text { Obs. } \\
\text { Wald-statistics }\end{array}$}} & 1313 & 1308 & 522 & 521 & 286 & 286 & 505 & 501 \\
\hline & & $172.4 * * *$ & $46.21 * * *$ & $42.43 * * *$ & $65.56^{* * *}$ & $310.72 * * *$ & $136.9 * * *$ & $103.4 * * *$ & $36.09 * * *$ \\
\hline
\end{tabular}




\section{DISCUSSIONS}

With respect to the first primary question of whether EP is positively or negatively related with FP, the results in the concurrent EP model (i.e., Table 3) clearly indicate that toxic releases are negatively related to both EBIT/Sales and Tobin's q at a significant level, providing strong evidence for the proponent's argument that benefits from corporate environmental investments surpass the costs. This result remained significant in both the pooled sample and sub-groups, even when controlling for the confounding effect of reactive and proactive corporate environmental strategies on EP, strengthening the proponent's view.

The present study further explored the relationship under the assumption that the magnitude of the relationship is not same across groups with heterogeneous EP. The results in Table 3 show that the magnitudes of the coefficients of the FP measures in both the HPII and PII peer groups are larger than those in both the pooled and Others groups. To further examine this finding, we calculated the elasticity of toxic releases with respect to the ratio change in FP in each sub-group and compared them across groups according to EP. The results from Model 2 in Table 3 show that an unit increase in EBIT/Sales (odd-numbered models), a short-term accounting-based FP measure, decreases EP by $1.53 \%$ at a significant margin $(\mathrm{p}<0.1)$. In Models 3,5 , and 7 , we checked the sign and significance of this coefficient according to the HPII group and found consistent results overall: we found a stronger relationship for the HPII and PII groups but not for the "Others" group. The marginal impact of Tobin's q is smaller, however, relative to that of EBIT/Sales, such that a unit increase in Tobin's q reduces EP by about $0.89 \sim 1 \%$. For a firm in the HPII group, this impact becomes stronger. The impact is also significant at the $5 \%$ level for a firm in the "Others" peer group. From these results, we tentatively conclude that firms in industries with high pollution intensity benefit more by doing good. This may be because they are closely monitored by external stakeholders or the public and their socially beneficial behaviors are evaluated in a more positive manner. However, the results also show that the significant relationship between EBIT/Sales and toxic releases is not observed in the "Others" peer group. This finding clearly suggests that we need to carefully interpret the results based on the aggregated sample without considering group heterogeneity. Otherwise, misinterpretation may lead to erroneous conclusions and steer policy makers, practitioners, and academic researchers in the wrong direction. Future studies can avoid the mixed results from this study by refining and reflecting the characteristics of the sample's data. This heterogeneous relationship can be important to corporate and government policy makers alike. They point to the dissociation of a large sector of polluting industries in America from well-intentioned efforts to create an environmentally sustainable industrial base.

The second goal of this study was to investigate whether FP precedes EP (Table 4) or vice versa (Table 5). Tables 4 and 5 present the results from Model 1 for the pooled sample, while Tables 4 and 5 present the results from Models 2, 3, and 4 for each sub-group with heterogeneous EP. What is immediately clear from Table 4 is that the results partially support the argument that a previous improvement in FP helps improve current EP: that is, the Granger causality effect of FP on EP depends on the sub-groups' heterogeneous EP. EBIT/Sales, for instance, is negatively related to current EP at a significant level in the HPII group and at a marginal level in the PII group. The results for Tobin's q are more striking: it is negatively related with toxic releases only for the HPII peer group. Especially, this outcome is not observed in the aggregated sample (i.e., Model 1a in Table 4). In the FP model (i.e., Table 5), we tested whether the preceding EP affects FP. The results show that the one-year lagged EP is negatively related at a marginal level only to short-run profitability (i.e., EBIT/Sales). In summary, the results if the Granger test show that the FP model is statistically weaker than the EP model.

As described earlier, a recent empirical study observed a dual causal relationship across firms in the Japanese toxic-generating industries that have different FP and EP results (Nakao et al., 2007). Our findings do not support this result but, rather, provide evidence to support a recent meta-study (Margolis et al., 2007) that argued that the "EP model (i.e., from FP $\rightarrow$ EP causal direction) is stronger than the other model (i.e., the reverse direction)." Further, our results show that the relatively stronger EP model also depends on sub-group differences in EP. Thus, our findings indicate that the conclusion for the Japanese case can be generally accepted. Notwithstanding the weak FP model, the results from both this study and a recent empirical study (Nakao et al., 2007) suggest that EP and FP are related endogenously depending on how a group is defined. Future studies could adopt a refined econometric analysis to clarify the endogenous relationship, given that the existing literature does not offer any statistical evidence that can explain the relatively weak relationship that doing good leads to doing better. The present results 
support the argument that consolidating and then analyzing sub-groups that have different EP, although easy for analysis and interpretation, can mask the true meaning of the results and lead to mixed results for the relationship between EP and FP at the aggregate level rather than disentangle the results. Therefore, future studies should review past research that assumes homogeneity. From the results of both the concurrent and lagged analyses, we can conclude that the relationship between FP and EP depends on the use of consistent FP measures, different analytic methods, and selected sample characteristics. For short-term accounting profitability, for example, the HPII and PII groups benefit financially (i.e., an increase in accounting-based profitability) from improving the natural environment. In contrast, efforts to reduce toxic releases is not financially attractive for firms in the "Others" peer group. The exact explanation for this result is beyond the scope of this study. The market-based measure is more consistently significant across all groups than the accounting-based measure is, but we see the opposite result in the lagged model. The results from Model 4 in Table 3, for example, show that EBIT/Sales does not significantly affect EP but Tobin's q does. Policy makers and stakeholders, therefore, need to carefully interpret the relationship between FP and EP regardless of how FP is measured. We hope that the mixed effects reported in this study may prompt practitioners to be more careful in attaching financial goals to their environmental strategies.

Like existing studies, this study has several limitations. First, although it controlled for industry, future studies should investigate whether the effect of FP on EP differs across heterogeneous EP peer groups within one industry. Second, this study measured EP based on objective EPA toxic releases; however, other objective proxies (e.g., legal penalty) should be alternatively used, given that EP can be measured in multi-dimensional ways. Therefore, researchers often recommend using multiple indicators and proxies to measure EP and FP (Griffin and Mahon, 1997; King and Lenox, 2002; Nakao et al., 2007). Third, generally, we observed the expected relationship in both the HPII and PII peer groups. One possible explanation for this is that firms in these industries are more likely to be influenced by the public media; therefore, their FP can be more promptly linked to worse or better EP. Perhaps, future studies could use data that represents other groups to obtain more reliable results. Finally, given that the current study focuses on heavy-polluting industries in the United States, future studies should consider heterogeneity when examining the relationship.

\section{CONCLUSION}

This study attempted to investigate two issues regarding the EP-FP relationship - its sign and directionusing longitudinal data for US heavy-polluting industries to provide statistical evidence. In this study, we used more relevant and well-known EP and FP measures and then examined them by a Granger causality test. The statistical evidence supports the proponent's argument that the two have a positive relationship. The evidence also supports the argument that the different and inconsistent FP measures explain the lack of consensus about the relationship in the literature. When controlling for heterogeneous groups' EP, the results showed that accounting- and market-based FP are related to EP differently. Generally, market-based FP has a more consistent relationship with EP in the concurrent model, but EBIT/Sales better represents the relationship in the time-lagged model. This finding reveals that recent past FP in terms of accounting-based profitability can be a better predictor of corporate EP.

The results of the Granger causality test clarify the direction of causation: EP is a function of preceding FP. The results indicate that EP and FP are endogenously related and that their relationship cannot be described simply as either "FP precedes and is a prerequisite of EP" or "EP is a precursor and a condition of FP," although the statement "EP temporarily precedes FP" is statistically weaker than the opposite statement. Finally, the effect of FP on EP does indeed differ across sub-groups with different EP, suggesting that generalizing from an aggregated industry while ignoring industry variation and diversity can distort the results and obscure the relationship between $\mathrm{EP}$ and FP.

\section{AUTHOR INFORMATION}

Kyungho Kim, DBA at Boston University, is an assistant professor at School of Business, Ajou University. His research areas include corporate strategy, international business strategy, corporate social responsibility, and environmental sustainability. 


\section{REFERENCES}

Allison, P.D. (1984). Event History Analysis: Regression for Longitudinal Event Data. SAGE: Newbury Park, CA.

Aragon-Correa, J.A., \& Sharma, S. (2003). A contingent resource-based view of proactive corporate environmental strategy. Academy of Management Review, 28(1), 71-88.

Arora, S., \& Cason, T.N. (1995). An experiment in voluntary environmental regulation: Participation in EPA'S 33/50 program. Journal of Environmental Economics and Management, 28(3), 271-286.

Bnnerjee, S.B., Lyer, E., \& Kashyap, R.K. (2003). Corporate environmentalism: antecedents and influence of industry type. Journal of Marketing, 67(2), 106-122.

Bansal, P., \& Roth, K. (2000). Why companies go green: a model of ecological responsiveness. Academy of Management Journal, 43(4), 717-736.

Birch, D., \& Moon, J. (2004). Introduction. Journal of Corporate Citizenship, 13(special issue), 18-22.

Bourgeois, L.J., \& Singh, J.V. (1983). Organizational slack and political behavior within top management groups. Paper presented at the Academy of Management Annual Meeting.

Bowen, F.E. (2002). Does size matter? Business \& Society, 41(1), 118-124.

Buysse, K., \& Verveke, A. (2003). Proactive environmental strategies: a stakeholder management perspective. Strategic Management Journal, 24(5), 453-470.

Cameron, A.C., \& Trivedi, P.K. (2009). Microeconometrics using stata. Stata Press.

Chatterji, A.K., Levine, D.I., \& Toffel, M.W. (2009). How well do social ratings actually measure corporate social responsibility? Journal of Economics \& Management Strategy, 18(1), 125-169.

Dahlmann, F. (2009). Oil prices \& greening: Antecedents of evolving corporate environmental strategy in the US. Paper presented at the Academy of Management Annual Meeting.

Daniel, F., Lohrke, F.T., Fornaciari, C.J., \& Turner, R.A. (2004). Slack resources and firm performance: a meta-analysis. Journal of Business Research, 57(6), 565-574.

Derwall, J., Guenster, N., Bauer, R., \& Koedijk, K. (2005). The eco-efficiency premium puzzle. Financial Analysis Journal, 61(2), 51-63.

Ditz, D., Ranganathan, J., \& Banks, D. (1995). Green ledgers: Case studies in corporate environmental accounting in Readings in Environmental Aspects: Environmental Auditing, Washington, D.C., (Eds.). World Resources Institute.

Fogler, H.R. \& Nutt, F. (1975). A note on social responsibility and stock valuation. Academy of Management Journal, $18(1), 155-160$.

Freedman, M., \& Jaggi, B. (1994). Analysis of the association between pollution performance and input cost factors: The case of electric utility plants. Journal of Accounting and Public Policy, 13(1), 31-48.

Friedman, M. (1970). The social responsibility of business is to increase its profits. New York Times Magazine, 32(13), $122-126$.

Galbreath, J. (2006). Does primary stakeholder management positively affect the bottom line? Management Decision, 44(8), 1106-1121.

Granger, C. (1969). Investigating causal relations by econometric models and cross-spectral methods. Econometrica, $37(3), 424-438$.

Greer, J., \& Bruno, K. (1996). Greenwash: The reality behind corporate environmentalism. Third World Network.

Griffin, J.J., \& Mahon, J.F. (1997). The corporate social performance and corporate financial performance debate. Business and Society, 36(1), 5-31.

Hart, S.L. (1995). A natural-resource-based view of the firm. Academy of Management Review, 20(4), 986-1014.

Hart, S. L., \& Ahuja, G. (1996). Does it pay to be green?: an empirical examination of the relationship between pollution prevention and firm performance. Business Strategy and the Environment, 5, 30-37.

Hillman, A.J., \& Keim, G.D. (2001). Shareholder value, stakeholder management, and social issues: what's the bottom line? Strategic Management Journal, 22(2), 125-139.

Judge, W.Q., \& Dougglas, T.J. (1998). Performance implications of incorporating natural environmental issues into the strategic planning process: an empirical assessment. Journal of Management Studies, 35(2), 241-262.

Keele, L., \& Kelly, N.J. (2006). Dynamic models for dynamic theories: The ins and outs of lagged dependent variables. Political Analysis, 14(2), 186-205.

Khanna, M., Quimio, W.R.H., \& Bojilova, D. (1998). Toxics release information: A policy tool for environmental protection. Journal of Environmental Economics and Management, 36(3), 243-266.

King, A.A., \& Lenox, M.J. (2000). Industry self-regulation without sanctions: The chemical industry's responsible care program. Academy of Management Journal, 43(4), 698-716.

King, A.A., \& Lenox, M.J. (2002). Exploring the locus of profitable pollution reduction. Management Science, 48(2), 289299. 
Konar, S., \& Cohen, M.A. (2001). Does the market value environmental performance? The Review of Economics and Statistics, 83(2), 281-289.

Levinson, A. (1996). Environmental regulations and manufacturer's location choices: Evidence from the census of manufacturing. Journal of Public Economics, 61(1), 5-29.

Lothe, S., Myrtveit, I., \& Trapani, T. (1999). Compensation systems for improving environmental performance. Business Strategy and the Environment, 8(6), 313-321.

Lu, H., \& Huang, H. (2008). Dirty industry migration globally and to China: An empirical study. International Review of Business Research Papers, 4(2), 176-202.

Mahapatra, S. (1984). Investor reaction to corporate social accounting. The Journal of Business Finance and Accounting, $11(1), 29-40$.

Margolis, J.D., Elfenbein, H.A., \& Walsh, J.P. (2007). Does it pay to be good? A meta-analysis and redirection of research on the relationship between corporate social and financial performance, Ann Arbor, 1001: 48109-41234.

Mattingly, J.E., \& Berman, S.L. (2006). Measurement of corporate social action. Business \& Society, 45(1), 20-46.

Mcquire, J.B., Sundgren, A., \& Schneeweis, T. (1988). Corporate social responsibility and firm financial performance. Academy of Management Journal, 31(4), 854-872.

Nakao, Y., Amano, A., Matsumura, K., Genba, K., \& Nakano, M. (2007). Relationship between environmental performance and financial performace: An empirical analysis of Japanese corporations. Business Strategy and the Environment, 16(2), 106-118.

Nehrt, C. (1998). Maintainability of first mover advantages when environmental regulations differ between countries. Academy of Management Review, 23(1), 77-97.

Orlitzky, M. (2001). Does firm size confound the relationship between corporate social performance and firm financial performance? Journal of Business Ethics, 33(2), 167-180.

Orlitzky, M., Schmidt, F.L., \& Rynes, S.L. (2003). Corporate social and financial performance: A meta-analysis. Organization Studies, 24(3), 403-441.

Papagiannakis, G., \& Voudouris, I. (2009). Evolving environmental responsiveness: A longitudinal study of corporate environmental strategy. 2009 Academy of Management Annual Meeting, Chicago, Illinois.

Palmer, K., Oates, W., \& Portney, P. (1995). Tightening environmental standards: The benefit-cost or the no-cost paradigm? Journal of Economic Perspectives, 9(4), 119-132.

Pogutz, S., \& Russo, A. (2009). Eco-efficiency vs. eco-effectiveness: Exploring the link between GHG emissions and firm performance. 2009 Academy of Management Annual Meeting, Chicago, Illinois.

Porter, M.E., \& Van Der Linde, C. (1995). Toward a new conception of the environment-competitiveness relationship. Journal of Economic Perspectives, 9(4), 97-118.

Rehbein, K., Waddock, S., \& Graves, S.B. (2004). Understanding shareholder activism: Which corporations are targeted? Business \& Society, 43(3), 239-267.

Russo, M.V., \& Fouts, P.A. (1997). A resource-based perspective on corporate environmental performance and profitability. Academy of Management Journal, 40(3), 534-559.

Sharma, D.S. (2002). The differential effect of environmental dimensionality, size, and structure on budget system characteristics in hotels. Management Accounting Research, 13(1), 101-130.

Shrivastava, P. (1995). Environmental technologies and competitive advantage. Strategic Management Journal, 16(1), 183-200.

Shropshire, C., \& Hillman, A.J. (2007). A longitudinal study of significant change in stakeholder management. Business \& Society, 46(1), 63-87.

Starik, M., \& Marcus, A.A. (2000). Introduction to the special research forum on the management of organizations in the natural environment: A field emerging from multiple paths, with many challenges ahead. Academy of Management Journal, 43(4), 539-546.

Strike, V.M., Gao, J., 7 Bansal, P. (2006). Being good while being bad: social responsibility and the international diversification of US firms. Journal of International Business Studies, 37(6), 850-862.

Tobey, J.A. (1990). The effects of domestic environmental policies on patterns of world trade: An empirical test. Kyklos, 43(2), 191-209.

Waddock, S.A., \& Graves, S.B. (1997). The corporate social performance-financial performance link. Strategic Management Journal, 18(4), 303-319.

Walley, N., \& Whitehead, B. (1994). It's not easy being green. Harvard Business Review, 72(3), 46-52. 


\section{NOTES}

